\title{
Review \\ Artificial Endoscopy and Inflammatory Bowel Disease: Welcome to the Future
}

\author{
Virginia Solitano $^{1} \mathbb{D}$, Alessandra Zilli ${ }^{2}$, Gianluca Franchellucci ${ }^{1}$, Mariangela Allocca ${ }^{2}$, Gionata Fiorino $^{2,3} \mathbb{D}$, \\ Federica Furfaro ${ }^{4}$ (D), Ferdinando D'Amico ${ }^{1,2}$, Silvio Danese ${ }^{2,3}$ and Sameer Al Awadhi ${ }^{5, *}$
}

check for updates

Citation: Solitano, V.; Zilli, A.; Franchellucci, G.; Allocca, M.; Fiorino, G.; Furfaro, F.; D'Amico, F.; Danese, S.; Al Awadhi, S. Artificial Endoscopy and Inflammatory Bowel Disease: Welcome to the Future. J Clin. Med. 2022, 11, 569. https:// doi.org/10.3390/jcm11030569

Academic Editor: Andrew Day

Received: 18 December 2021

Accepted: 18 January 2022

Published: 24 January 2022

Publisher's Note: MDPI stays neutral with regard to jurisdictional claims in published maps and institutional affiliations.

Copyright: (C) 2022 by the authors. Licensee MDPI, Basel, Switzerland. This article is an open access article distributed under the terms and conditions of the Creative Commons Attribution (CC BY) license (https:// creativecommons.org/licenses/by/ $4.0 /)$
1 Department of Biomedical Sciences, Humanitas University, 20090 Pieve Emanuele, Italy; virginia.solitano@humanitas.it (V.S.); gianluca.franchellucci@humanitas.it (G.F.) ferdinando.damico@humanitas.it (F.D.)

2 Gastroenterology and Endoscopy, IRCCS Ospedale San Raffaele, 20132 Milan, Italy; zilli.alessandra@hsr.it (A.Z.); allocca.mariangela@hsr.it (M.A.); gionataf@gmail.com (G.F.); sdanese@hotmail.com (S.D.)

3 Università Vita-Salute San Raffaele, 20132 Milan, Italy

4 Humanitas Clinical and Research Centre, 20089 Milan, Italy; federica.furfaro@humanitas.it

5 Digestive Diseases Unit, Rashid Hospital, Dubai 003206, United Arab Emirates

* Correspondence: saalawadhi@dha.gov.ae

\begin{abstract}
Artificial intelligence (AI) is assuming an increasingly important and central role in several medical fields. Its application in endoscopy provides a powerful tool supporting human experiences in the detection, characterization, and classification of gastrointestinal lesions. Lately, the potential of AI technology has been emerging in the field of inflammatory bowel disease (IBD), where the current cornerstone is the treat-to-target strategy. A sensible and specific tool able to overcome human limitations, such as AI, could represent a great ally and guide precision medicine decisions. Here we reviewed the available literature on the endoscopic applications of AI in order to properly describe the current state-of-the-art and identify the research gaps in IBD at the dawn of 2022.
\end{abstract}

Keywords: inflammatory bowel disease; artificial intelligence; endoscopy; capsule endoscopy; machine learning

\section{Introduction}

Crohn's disease (CD) and ulcerative colitis (UC) are chronic inflammatory bowel disease (IBD), with increasing incidence all around the world and a great impact on general well-being, social functioning, and utilization of healthcare resources [1,2]. The diagnosis of IBD is a daily challenge for physicians, being based on different elements such as clinical data, biochemical values, radiology, endoscopy, and histology [3]. Among them, endoscopy represents a cornerstone in the diagnosis and follow-up of CD and UC [4,5].

In the last five years, the concept of endoscopy has evolved from a traditional one to a new idea based on artificial intelligence (AI). AI is defined as any machine that has cognitive functions mimicking humans for problem solving or learning [6]. AI has already been tested in several fields of endoscopy, such as in the detection of Barrett's esophagus [7] or the evaluation of adenoma detection rate during colonoscopy [8,9].

Attention has shifted to the potential role of AI in the field of IBD where endoscopic activity is based on several scores, such as the Mayo endoscopic subscore (MES), the Ulcerated Colitis Endoscopic Index of Severity (UCEIS), the Crohn's Disease Endoscopic Index of Severity (CDEIS), the Lewis score, and the Capsule Endoscopy Crohn's Disease Activity Index (CECDAI) [10-14]. The reason for this large number of scores lays in the need for establishing a strict definition of disease activity, thus reducing the interobserver variability and having a solid comparative analysis of different patients or studies [15]. In this context AI could be a great step forward in the research of homogeneity and reproducibility of endoscopic data. This article aims to summarize the literature data on AI 
endoscopic applications in the field of IBD, underlining the strengths and limitations of the currently available tools at the dawn of 2022.

\section{What Is Artificial Intelligence and Its Current Application in Endoscopy?}

AI-assisted endoscopy is based on computer algorithms that perform as human brains do [16]. They react (output) to what they receive as information (input) and what they have learned when built. The fundamental principle of this technology is "machine learning" (ML) [17].

There are many different ML methods (Table 1) and one of the most popular is the use of artificial neural networks (ANN) [18]. ANN is based on multiple interconnected layers of algorithms, which process data in a specific pattern and feed data so that the system can be trained to carry out a specific task [19]. Another diffuse ML method is the Supportvector machine (SVM), which is used for classifying data sets by creating a line or plane to separate data into distinct classes [20]. An evolution of ML is deep learning (DL): a complex, multilayer neural network architecture learns representations of data automatically by transforming the input information into multiple levels of abstractions [21,22]. An evolution of the simpler ANN is the convolution neural network $(\mathrm{CNN})$, inspired by the response of human visual cortex neurons to a specific stimulus and being able to convolve the input and pass its result to the next layer $[19,23]$.

Table 1. Algorithms involved in machine learning process.

\begin{tabular}{cr}
\hline Supervised & The algorithm is trained by labeling data tagged with the correct answer \\
\hline Semisupervised & The algorithm is trained without marking the training data \\
\hline Unsupervised & The algorithm is structured on a large amount of unlabeled data based on \\
& a small amount of labeled data \\
\hline
\end{tabular}

Based on this technology, three kinds of tools have been generated to support endoscopy in each part of its activity [24-26]:

- $\quad$ Computer-aided detection (CADe), which detects gastrointestinal lesions;

- Computer-aided diagnosis (CADx), which characterizes gastrointestinal lesions;

- $\quad$ Computer-aided monitoring (CADm), which evaluates the procedure and the endoscopist, thus improving the quality of endoscopy.

In particular, CADe and CADx are the best developed systems with many experiences around the world demonstrating their better performance than the human eye [9,27-29]; for example, the GI-Genius Medtronic system reached a sensibility of $99.7 \%$ in polyps detection as shown by Hassan et al. [27]. The application fields of AI are expanding rapidly and IBD is the next target of this innovative technology.

\section{AI in the Diagnosis of IBD}

One of the first applications of AI has been the attempt to facilitate the diagnosis of IBD and the differential diagnosis between CD and UC. In the model of Mossotto [30], three supervised ML models were developed utilizing endoscopic data only, histological only, and combined endoscopic/histological with an accuracy of $71.0 \%, 76.9 \%$, and $82.7 \%$, respectively [30]. The model combining endoscopic and histological data was tested on a statistically independent cohort of 48 pediatric patients from the same clinic, with an accuracy of about $83.3 \%$ in patients' classification.

Quénéhervé and colleagues [31] tried to design a model to diagnose IBD and establish differential diagnoses between CD vs. UC. They based their study on confocal laser endomicroscopy (CLE), which is an adaptation of light microscopy whereby focal laser illumination is combined with pinhole limited detection to geometrically reject out-of-focus light [32]. The authors built a score based on 14 functional and morphological parameters to perform a quantitative analysis of the mucosa called cryptometry and detect a diagnosis of IBD with a sensitivity and a specificity to near $100 \%$. Moreover, this study reached a 
sensitivity of $92.3 \%$ and a specificity of $91.3 \%$ in the differential diagnosis between CD and UC.

Diagnosis of IBD can be a complex and challenging procedure due to its heterogeneous presentation. It is generally believed that making a correct diagnosis requires information on the endoscopic and histological features, together with clinical and biochemical data. AI support may be helpful in the diagnostic process by combining all suggestive features intelligently.

\section{AI in $\mathrm{UC}$, State-of-the-Art}

As previously underlined, endoscopy plays a fundamental role in the diagnosis and assessment of IBD activity [5]. According to this concept, endoscopy should guarantee an exact staging of the disease and a high level of concordance between different operators. Indeed, the definition of recurrence or the assessment of remission are cornerstones in the disease management, thus guiding the next clinical or surgical decisions [33,34].

In the study of Ozawa, the authors designed a CAD system using a CNN and evaluated its performance in the identification of normal or inflamed mucosa, using a large dataset of endoscopic images from patients with UC [35]. The performance of this new tool was valuable, with areas under the receiver operating characteristic curves (AUROCs) of 0.86 and 0.98 in the identification of MES 0 (completely normal mucosa) and MES 0-1 (mucosal healing state), respectively [35]. In a similar experience from Stidham et al. [36] a CNN showed an AUROC of 0.96 in distinguishing endoscopic remission (MES $=0$ or 1 ) from moderate to severe disease (MES $=2$ or 3 ), with a good weighted $\kappa$ agreement between the $\mathrm{CNN}$ and the adjudicated reference score for identifying exact MES $(\kappa=0.84 ; 95 \% \mathrm{CI}$, $0.83-0.86$ ). The application of this $\mathrm{CNN}$ to the entirety of the colonoscopy videos had high accuracy in identifying moderate to severe disease with an AUROC of 0.97 [36].

Moreover, Gottlieb and colleagues [37] developed another recurrent neural network able to predict MES and UCEIS from entire endoscopy videos and not only from images. The system automatically selected the frame to be analyzed and scores were calculated on the colon section, showing high agreement with the human central reader score [37]. Similarly, a fully automated video analysis system was developed to assess the grade of UC activity and predicted MES in $78 \%$ of videos $(\kappa=0.84)$. In external clinical trial videos, reviewers agreed on MES in $82.8 \%$ of videos $(\kappa=0.78)$ [38]. Automated MES grading of clinical trial videos (often low resolution) correctly distinguished remission (MES $=0$ or 1 ) vs. active disease (MES $=2$ or 3 ) in $83.7 \%$ of videos.

Not only were automated systems able to assess endoscopic activity from still images [39], but they were also able to predict a binary version of the MES directly analyzing a raw colonoscopy video, resulting in a high level of accuracy (AUC of 0.94 for MES $\geq 1$ and 0.85 for MES $\geq 2$ and MES $\geq 3$ ) [40]. Looking forward, it seems that AI can also guide real-time therapy decisions in patients with UC in clinical remission by helping to stratify the relapse risk one year after AI-assisted colonoscopy [41].

Other experiences pushed forward the application of AI in the prediction of histology. Indeed, Takenaka and colleagues [42] designed a deep neural network algorithm, defined as DNUC, based on more than 40,000 images from colonoscopies and 6000 biopsies of 875 patients prospectively collected. AI system evaluations were matched with the UCEIS score expressed for each image by three expert endoscopists and with the Geboes score determined by pathologists [43]. The DNUC revealed an accuracy of $90.9 \%$ and $92.9 \%$ in the detection of endoscopic and histological remission, respectively. In addition, Maeda et al. [44] developed a CADx system to predict persistent histological inflammation using endocytoscopy in 187 retrospectively collected patients. Endocytoscopy is one of the most valuable technologies, although it is not widely available in endoscopic departments. Providing ultra-high-resolution white light images (520x), endocytoscopy allows the socalled virtual histology or optical biopsy [45]. The results obtained by the CAD algorithm were compared with the Geboes score defined by five expert pathologists, blinded from 
endoscopist results. The algorithm showed a sensitivity of $74 \%$ and a specificity of $97 \%$, with high level of reproducibility and interobserver agreement $(\kappa$ value $=1)$.

Honzawa and colleagues [46] moved forward with the AI-application in trying to differentiate between MES 0 and MES 1 in patients with UC in clinical remission. The authors investigated the correlation among the so-called MAGIC score (Mucosal Analysis of Inflammatory Gravity by i-scan TE-c Image), MES, and histological Geboes score. Interestingly, the MAGIC score, based on the level of mean inflammation derived from all the pixels, was significantly higher in the MES 1 group than in the MES 0 group $(p=0.0034)$, with a significant correlation with histology $(p=0.015)$.

Similar to the color map of the MAGIC score, a validation study [47] elaborated an operator-independent, computer-based tool, named Red Density (RD), that determined disease activity in UC according to a redness map and vascular pattern recognition. The RD score, which is different from the previous exposed experiences as it is based on pure physics parameters, significantly correlated with the histological scoring systems (Robarts Histopathology index, $\mathrm{r}=0.74$ ) and with MES and UCEIS endoscopic scores with $\mathrm{r}=0.76$ and 0.74 , respectively. Some weak points of this work are the monocentric experience, the small population (29 patients), and the analysis being performed only on the single picture and not on the entire colonic segment. However, this study represents an important application of AI as testified by the high level of performance. Notably, the algorithm structure does not require as much information as the CNN system due to the possibility of sequential modulation of the algorithm during the development.

Finally, a multicenter study in inactive patients with UC (PRognOstiC valuE of rEd Density in Ulcerative Colitis: PROCEED-UC; NCT04408703) is planned to assess the predictive value of the RD score for sustained clinical remission. It is plausible that the RD score might be used in the future as the first objective operator-independent endoscopic target in a treat-to-target strategy in UC. The main characteristics of the studies on endoscopic AI application in IBD are summarized in Table 2.

Table 2. Most relevant studies on endoscopic AI application in IBD.

\begin{tabular}{|c|c|c|c|c|}
\hline Author (Year) & Study Design & Population & Aim & Results \\
\hline Mossotto et al. (2017) & $\begin{array}{c}\text { Prospective cohort } \\
\text { study }\end{array}$ & 287 paediatric IBD & $\begin{array}{c}\text { To develop a ML model } \\
\text { to classify disease } \\
\text { subtypes }\end{array}$ & $\begin{array}{c}\text { Classification accuracy with } \\
\text { supervised ML models of } \\
71.0 \%, 76.9 \% \text {, and } 82.7 \% \\
\text { utilizing endoscopic data only, } \\
\text { histological only, and } \\
\text { combined } \\
\text { endoscopic/histological data, } \\
\text { respectively }\end{array}$ \\
\hline $\begin{array}{l}\text { Quénéhervé et al. } \\
\text { (2019) }\end{array}$ & $\begin{array}{l}\text { Retrospective } \\
\text { cohort study }\end{array}$ & $\begin{array}{l}23 \text { CD patients, } 27 \\
\text { UC patients, and } 9 \\
\text { control patients }\end{array}$ & $\begin{array}{l}\text { To test computer-based } \\
\text { analysis of CLE images } \\
\text { and discriminate } \\
\text { healthy subjects vs. } \\
\text { IBD, and UC vs. CD }\end{array}$ & $\begin{array}{c}\text { Sensitivity of } 100 \% \text { and } \\
\text { specificity of } 100 \% \text { in IBD } \\
\text { diagnosis; } \\
\text { sensitivity of } 92 \% \text { and } \\
\text { specificity of } 91 \% \text { in IBD } \\
\text { differential diagnosis }\end{array}$ \\
\hline Ozawa et al. (2019) & $\begin{array}{l}\text { Retrospective } \\
\text { cohort study }\end{array}$ & $\begin{array}{l}\text { 26,304 colonoscopy } \\
\text { images from a } \\
\text { cumulative total of } \\
841 \text { UC patients }\end{array}$ & $\begin{array}{l}\text { To test a CNN-based } \\
\text { CAD system in } \\
\text { identification of } \\
\text { endoscopic } \\
\text { inflammation severity }\end{array}$ & $\begin{array}{l}\text { AUROCs of } 0.86 \text { and } 0.98 \text { to } \\
\text { identify MES } 0 \text { and } 0-1, \\
\text { respectively }\end{array}$ \\
\hline Stidham et al. (2019) & $\begin{array}{l}\text { Retrospective } \\
\text { cohort study }\end{array}$ & $\begin{array}{l}\text { 16,514 images from } \\
3082 \text { UC patients }\end{array}$ & $\begin{array}{l}\text { To test DL models in } \\
\text { grading endoscopic } \\
\text { severity of UC }\end{array}$ & $\begin{array}{c}\text { AUROCs of } 0.96, \text { PPV of } 0.87 \text {, } \\
\text { sensitivity of } 83.0 \% \text {, specificity } \\
\text { of } 96.0 \% \text {, and NPV of } 0.94 \text { in } \\
\text { distinguishing endoscopic } \\
\text { remission from MES } 2-3\end{array}$ \\
\hline
\end{tabular}


Table 2. Cont.

\begin{tabular}{|c|c|c|c|c|}
\hline Author (Year) & Study Design & Population & Aim & Results \\
\hline Gottlieb et al. (2021) & $\begin{array}{l}\text { Phase II } \\
\text { randomized } \\
\text { controlled study }\end{array}$ & 249 UC patients & $\begin{array}{c}\text { To test a recurrent } \\
\text { neural network model } \\
\text { in predicting } \\
\text { MES and UCEIS from } \\
\text { individual full-length } \\
\text { endoscopy videos }\end{array}$ & $\begin{array}{c}\text { Excellent agreement metric } \\
\text { with a QWK of } 0.84 \\
\text { for MES and } 0.85 \text { for UCEIS }\end{array}$ \\
\hline Yao et al. (2021) & $\begin{array}{l}\text { Phase II } \\
\text { randomized } \\
\text { controlled study }\end{array}$ & $\begin{array}{c}315 \text { videos from } 157 \\
\text { UC patients }\end{array}$ & $\begin{array}{l}\text { To test a fully } \\
\text { automated video } \\
\text { analysis system for } \\
\text { grading endoscopic } \\
\text { disease }\end{array}$ & $\begin{array}{l}\text { Excellent performance with a } \\
\text { sensitivity of } 0.90 \text { and } \\
\text { specificity of } 0.87 ; \\
\text { correct prediction of MES in } \\
78 \% \text { of videos }(\mathrm{k}=0.84)\end{array}$ \\
\hline Bhambhani et al. (2021) & $\begin{array}{l}\text { Retrospective } \\
\text { cohort study }\end{array}$ & $\begin{array}{l}777 \text { endoscopic } \\
\text { images from } 777 \\
\text { UC patients }\end{array}$ & $\begin{array}{l}\text { To test a DL models in } \\
\text { the automated grading } \\
\text { of each individual MES }\end{array}$ & $\begin{array}{c}\text { AUC of } 0.89,0.8 \text {, and } 0.96 \text { for } \\
\text { classification of MES } 1,2 \text {, and } \\
\text { 3, respectively; } \\
\text { overall accuracy of } 77.2 \%\end{array}$ \\
\hline Becker et al. (2021) & $\begin{array}{c}\text { Prospective cohort } \\
\text { study }\end{array}$ & $\begin{array}{l}1672 \text { videos from } \\
1105 \text { UC patients }\end{array}$ & $\begin{array}{l}\text { To test a DL-based } \\
\text { system on raw } \\
\text { endoscopic videos }\end{array}$ & $\begin{array}{c}\text { AUC of } 0.84 \text { for } \mathrm{MES} \geq 1,0.85 \\
\text { for } \mathrm{MES} \geq 2 \text { and } 0.85 \text { for } \\
\mathrm{MES} \geq 3\end{array}$ \\
\hline Maeda et al. (2021) & $\begin{array}{c}\text { Prospective cohort } \\
\text { study }\end{array}$ & 145 UC patients & $\begin{array}{l}\text { To test } \mathrm{AI} \text { in stratifying } \\
\text { the relapse risk of } \\
\text { patients in clinical } \\
\text { remission }\end{array}$ & $\begin{array}{l}\text { Relapse rate significantly } \\
\text { higher in the AI-active group } \\
\text { than in the AI-healing group } \\
(28.4 \% \text { vs. } 4.9 \%, p<0.001)\end{array}$ \\
\hline Takenaka et al. (2020) & $\begin{array}{l}\text { Prospective cohort } \\
\text { study }\end{array}$ & $\begin{array}{l}\text { 40,758 images of } \\
\text { colonoscopies and } \\
6885 \text { biopsy results } \\
\text { from } 2012 \mathrm{UC} \\
\text { patients }\end{array}$ & $\begin{array}{l}\text { To test a DNN system } \\
\text { based on endoscopic } \\
\text { images of UC for } \\
\text { predicting endoscopic } \\
\text { and histological } \\
\text { remission }\end{array}$ & $\begin{array}{c}\text { Accuracy of } 90.1 \% \text { and } \kappa \\
\text { coefficient of } 0.798 \text { for } \\
\text { endoscopic remission; } \\
\text { accuracy of } 92.9 \% \text { and } \mathrm{k} \\
\text { coefficient of } 0.85 \text { for } \\
\text { histological remission }\end{array}$ \\
\hline
\end{tabular}

Retrospective $\quad 187$ UC patients in predicting persistent cohort study histologic inflammation endoscopic imaging system using the iscan TE-c (MAGIC score) to patients with quiescent

To test a RD algorithm based on channel of the

Bossuyt et al. (2020) Prospective cohort 29 UC patients and study
6 controls
52 UC patients in cohort study clinical remission using EC

To test a new quantify mucosal inflammation in UC

Sensitivity, specificity, and accuracy of $74 \%, 97 \%$, and $91 \%$, respectively; $\mathrm{k}=1$

MAGIC score significantly higher in the

MES 1 than in the MES 0 group $(p=0.0034)$;

MAGIC score significantly correlated with the Geboes score $(p=0.015)$

Good correlation between RD and RHI $(\mathrm{r}=0.74, p<0.0001)$, $\operatorname{MES}(r=0.76, p<0.0001)$, and values and pattern recognition from endoscopic images

$$
\text { UCEIS }
$$$$
(\mathrm{r}=0.74, p<0.0001)
$$

Abbreviations: AUC: area under the curve; AUROC: areas under the receiver operating characteristic curve CAD: computer-assisted diagnosis; CD: Crohn's disease; CLE: confocal laser endomicroscopy; CNN: convolution neural network; DL: deep learning; DNN: deep neural network; IBD: inflammatory bowel disease; MAGIC: Mucosal Analysis of Inflammatory Gravity by i-scan TE-c Image; MES: Mayo endoscopic subscore; ML: machine learning; NPV: negative predictive value; PPV: positive predictive value; QWK: quadratic weighted kappa, RD: red density; RHI: Robarts Histopathology index; UC: ulcerative colitis, UCEIS: Ulcerative Colitis Endoscopic Index of Severity. 


\section{AI in CD, State-of-the-Art}

In the field of CD, AI has been mostly applied on video capsule technology (Table 3), which has been assuming an important role both in the diagnosis and assessment of mucosa healing in the small bowel [48]. In the current European Crohn's and Colitis Organisation (ECCO) guidelines, patients suspected to have $\mathrm{CD}$ but with a negative endoscopy should undergo a second level diagnostic method such as magnetic resonance imaging (MRI) or video capsule endoscopy [4]. Moreover, even in cases of normal imaging tests, such as MRI and clinical signs suspicious of small bowel CD (e.g., elevated calprotectin and/or unexplained iron deficiency anemia), video capsule endoscopy is indicated to exclude small bowel involvement [4]. However, the use of video capsules has some limitations, such as the collection of a huge amount of data and the duration of the analysis [48]. AI may overcome these barriers by selecting the frame or the part of video needed for the assessment and cutting off the time for diagnosis, thus requiring a limited amount of data to store.

Table 3. Most relevant studies on video capsule AI application in CD.

\begin{tabular}{|c|c|c|c|c|}
\hline Author (Year) & Study Design & Population & Aim & Results \\
\hline Girgis et al. (2010) & $\begin{array}{l}\text { Retrospective } \\
\text { cohort study }\end{array}$ & $\begin{array}{l}47 \text { videos from } 29 \\
\mathrm{CD}, 17 \text { control, } 1 \\
\text { celiac patient }\end{array}$ & $\begin{array}{l}\text { To test a system able to } \\
\text { detect inflammation among } \\
\text { the thousands of images } \\
\text { acquired by the WCE }\end{array}$ & $\begin{array}{l}\text { Total accuracy, specificity, } \\
\text { and sensitivity of } 87 \%, 93 \% \text {, } \\
\text { and } 80 \% \text {, respectively }\end{array}$ \\
\hline Kumar et al. (2012) & $\begin{array}{l}\text { Retrospective } \\
\text { cohort study }\end{array}$ & $\begin{array}{c}47 \text { videos, } \\
30 \text { of which } \\
\text { contained } C D \\
\text { lesions }\end{array}$ & $\begin{array}{l}\text { To test a supervised } \\
\text { classification for CD lesions } \\
\text { and for quantitative } \\
\text { assessment of lesion severity }\end{array}$ & $\begin{array}{l}\text { Good precision ( }>90 \% \text { for } \\
\text { lesion detection) and recall } \\
(>90 \%) \text { for lesions of } \\
\text { varying severity }\end{array}$ \\
\hline Charisis et al. (2016) & $\begin{array}{l}\text { Retrospective } \\
\text { cohort study }\end{array}$ & $\begin{array}{l}\text { 800-image database } \\
\text { from } 13 \text { CD patients }\end{array}$ & $\begin{array}{c}\text { To test HAF-DLac approach } \\
\text { for automated lesion } \\
\text { detection }\end{array}$ & $\begin{array}{c}\text { Accuracy, sensitivity, } \\
\text { specificity, and precision of } \\
93.8 \%, 95.2 \%, 92.4 \% \text {, and } \\
92.6 \% \text {, respectively }\end{array}$ \\
\hline Klang et al. (2020) & $\begin{array}{l}\text { Retrospective } \\
\text { cohort study }\end{array}$ & $\begin{array}{l}\text { 17,640 CE images } \\
\text { from } 49 \text { CD patients }\end{array}$ & $\begin{array}{l}\text { To test a CNN in classifying } \\
\text { images into either normal } \\
\text { mucosa or mucosal ulcers }\end{array}$ & $\begin{array}{c}\text { AUC of } 0.99 \text { and accuracy } \\
\text { ranging from } 95.4 \% \text { to } \\
96.7 \%\end{array}$ \\
\hline Klang et al. (2021) & $\begin{array}{l}\text { Retrospective } \\
\text { cohort study }\end{array}$ & 27,892 CE images & $\begin{array}{l}\text { To test a DLN for detecting } \\
\text { CE images of strictures }\end{array}$ & $\begin{array}{c}\text { For classification of } \\
\text { strictures vs. nonstrictures, } \\
\text { average accuracy of } 93.5 \% \\
( \pm 6.7 \%)\end{array}$ \\
\hline Barash et al. (2021) & $\begin{array}{l}\text { Retrospective } \\
\text { cohort study }\end{array}$ & $\begin{array}{l}\text { 17,640 CE images } \\
\text { from } 49 \text { CD patients }\end{array}$ & $\begin{array}{c}\text { To test a CNN in } \\
\text { automatically grading } \\
\text { images of ulcers and } \\
\text { compare the resulting } \\
\text { algorithm with a consensus } \\
\text { reading }\end{array}$ & $\begin{array}{l}\text { Algorithm accuracy of } 0.91 \\
\text { for grade } 1 \text { vs. grade } 3 \\
\text { ulcers, of } 0.78 \text { for grade } 2 \\
\text { vs. grade } 3 \text {, and of } 0.62 \text { for } \\
\text { grade } 1 \text { vs. grade } 2\end{array}$ \\
\hline Majtner et al. (2021) & $\begin{array}{l}\text { Retrospective } \\
\text { cohort study }\end{array}$ & $\begin{array}{l}7744 \text { images from } \\
38 \text { CD patients } \\
\text { (small bowel } 4972, \\
\text { colon } 2772 \text { ) }\end{array}$ & $\begin{array}{l}\text { To test the ability of a DL } \\
\text { framework to detect lesions } \\
\text { with panenteric capsule } \\
\text { endoscopy }\end{array}$ & $\begin{array}{c}\text { Diagnostic accuracy of } \\
98.5 \% \text { for small bowel and } \\
98.1 \% \text { for colon }\end{array}$ \\
\hline Ferreira JPS et al. (2021) & $\begin{array}{l}\text { Retrospective } \\
\text { cohort study }\end{array}$ & 8085 images & $\begin{array}{l}\text { To develop and validate a } \\
\text { CNN for ulcer and erosion } \\
\text { detection using panenteric } \\
\text { capsule endoscopy images }\end{array}$ & $\begin{array}{l}\text { Model sensitivity, } \\
\text { specificity, precision, and } \\
\text { accuracy of } 90.0 \%, 96.0 \% \text {, } \\
97.1 \% \text {, and } 92.4 \% \text {, } \\
\text { respectively }\end{array}$ \\
\hline
\end{tabular}

Abbreviations: AUC: area under the curve; CD: Crohn's Disease; CE: capsule endoscopy; CNN: convolutional neural network; DL: deep learning; DLac: differential lacunarity; DLN: deep learning network; HAF: hybrid adaptive filtering; WCE: wireless capsule endoscopy. 
The first experience was conducted about 10 years ago. Girgis et al. [49] built a system that identified the inflamed regions after a SVM training, with an accuracy of 87\%, sensitivity of $93 \%$, and specificity of $80 \%$. Two years later, Kumar et al. [50] developed a similar system with a precision of about $90 \%$ in detecting CD lesions. Lately, several studies have been conducted for the development of systems able to automatically detect ulcers and/or aphthae and to grade mucosal damage.

A novel filtering process, called hybrid adaptive filtering (HAF), was proposed for efficient extraction of lesion-related characteristics using wireless capsule endoscopy. This system was trained on 800 images collected by 13 different patients and offered high performances in the detection of severe lesions (93.8\% of accuracy, $95.2 \%$ of sensitivity, $92.4 \%$ specificity, and $92.6 \%$ of precision) [51]. The group of Klang provided two experiences in this direction $[52,53]$. The former showed an AUC of 0.99 with an accuracy ranging from $95.4 \%$ to $96.7 \%$ in classifying images into either normal mucosa or mucosa with ulcers [52]. The latter exhibited a good accuracy of $93.5 \%[ \pm 6.7 \%]$ in classifying strictures vs. nonstrictures [53].

A CNN was trained to detect erosions and ulcers, demonstrating performances comparable with the activity of two expert gastroenterologists, with an AUC of 0.96 for the detection of abnormalities [54]. Interestingly, a consensus reading was used to train another $\mathrm{CNN}$ in automatic grading of images of CD ulcers. The resulting algorithm was tested against capsule readers, showing high accuracy in classifying severe ulcers $(0.91$ for grade 1 vs. grade 3 ulcers compared to 0.6 for grade 1 vs. 2) [55].

DL methods for autonomous detection and classification of CD lesions have also been applied to panenteric capsule endoscopy system that is now available allowing simultaneous investigation of the small bowel and colon. AI technology has increased the diagnostic yield and reduced interobserver variability in this integrated procedure [56,57].

Not only did AI show a high level of performance, but also a significantly faster reading with an average time of 3.5 minutes against 50 minutes for a full video of capsule endoscopy [52,58].

Some limitations of these works warrant attention. Firstly, they were made on single images and not on the entire video so that the analysis was not able to provide an overall evaluation of the validated scores for video capsule (e.g., the Lewis score). Moreover, they are retrospective cohort studies based on restricted samples of patients.

Nevertheless, all these experiences could give a great impulse to capsule endoscopy in $\mathrm{CD}$. The inflammation in the proximal bowel is correlated with a worst prognosis and a higher surgical risk [59], therefore a modern method of analysis with high sensitivity and specificity is eagerly awaited in clinical practice [60].

\section{AI for the Detection of Neoplasms in Long-Standing IBD}

Given the increased risk for developing colorectal neoplasia, surveillance colonoscopy plays an important role in the management of UC [61]. The gold standard method for dysplasia surveillance is chromoendoscopy, which utilizes indigo carmine or methylene to better define the superficial gastrointestinal mucosa [62]. New endoscopic imaging technologies such as virtual chromoendoscopy, autofluorescence imaging, CLE, and endocytoscopy are now emerging, but there are only a few reports about the application of AI-assisted colonoscopy techniques for the early diagnosis of colorectal cancer [5].

The AI capacity has been tested in the detection of colorectal neoplasia (Figure 1) but not specifically in patients with IBD.

The first experience is a case report of Maeda and colleagues [63] where the EndoBRAIN eye system was tested for detecting dysplasia in a patient with long-standing UC. This system is able to identify colorectal lesions with high accuracy in general population [64], but in this case it proved to support endoscopists in the identification of UC-associated dysplasia, which is not always easy to detect due to its flat appearance and unclear boundaries. 


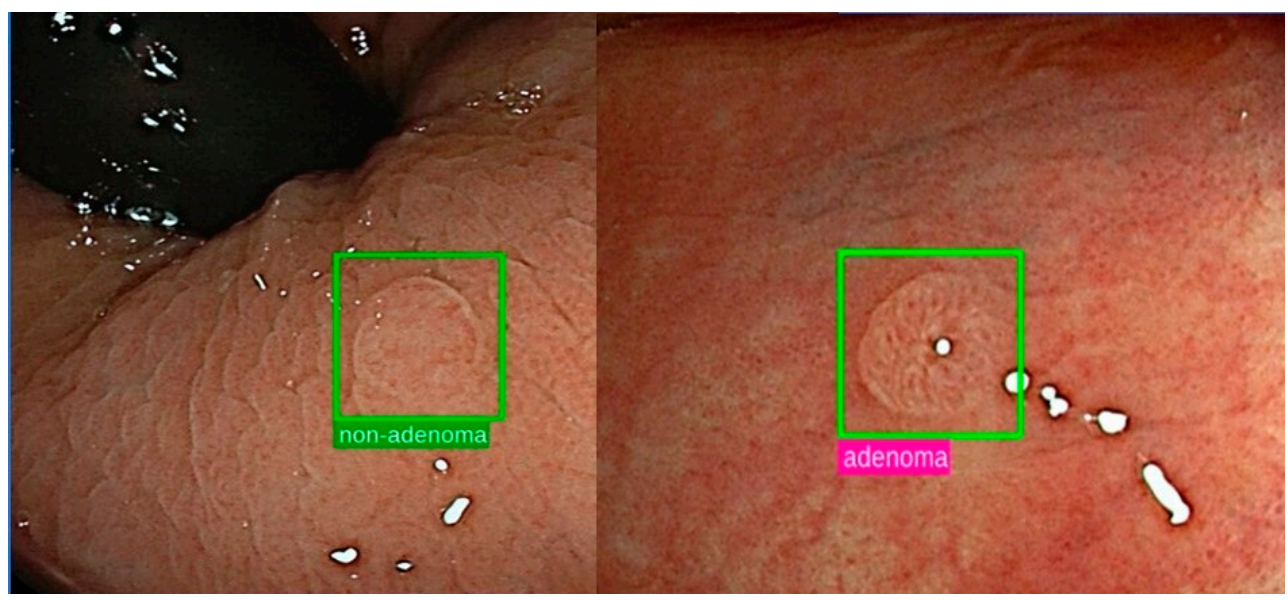

Figure 1. Representative images of AI-support in colorectal polyps' characterization.

Another example of AI-support in the detection of dysplasia was reported by Fukunaga [65]. In this case report, EndoBRAIN system helped endocitoscopy in the detection of high-grade dysplasia in a patient with long-standing UC who subsequently underwent an endoscopic submucosal dissection. To note, colitis-associated colorectal cancer may be generally difficult to diagnose due to consequences of inflammation on mucosal appearance (Figure 2) and the use of EndoBRAIN could help non-expert endoscopists to identify lesions. These experiences underline the potential and future role of AI in the colitis-associated dysplasia and neoplasia detection during IBD surveillance.

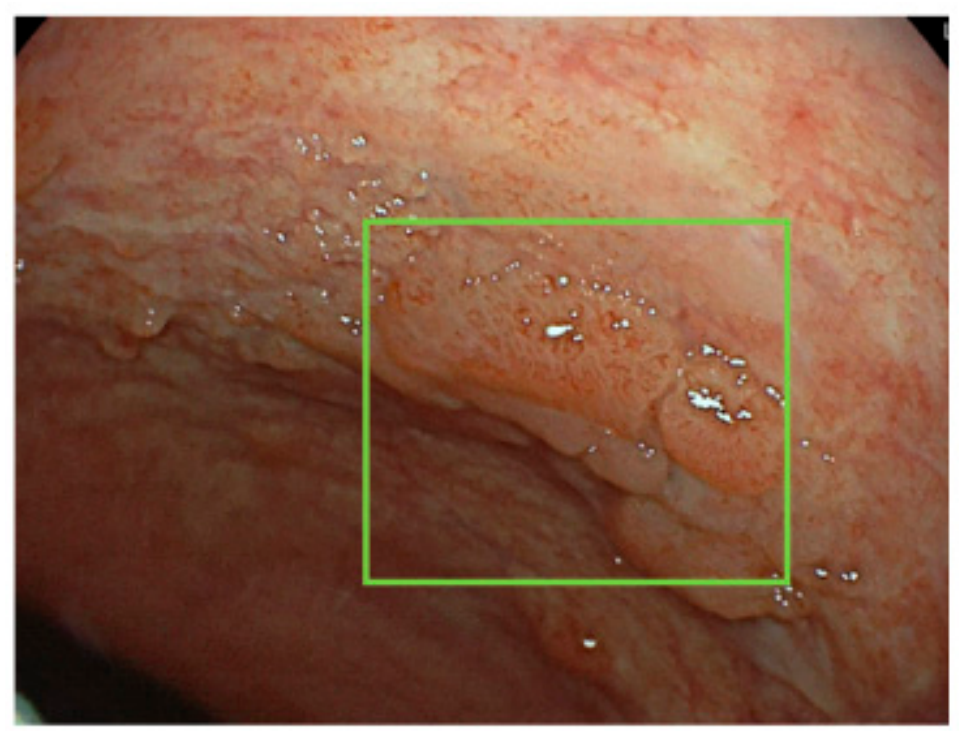

Figure 2. Representative image of colitis-associated dysplasia in a patient with long-standing UC.

\section{Conclusions and Future Perspectives}

$\mathrm{AI}$ is a cornerstone revolution in endoscopy. In the field of IBD, its primary applications are providing great results in the diagnosis and staging of the disease. In a field of medicine where the current mantra is the treat-to-target strategy and where treatment directions are guided by endoscopic remission, a sensible and specific tool able to overcome human limitations could represent a great ally. High-performing diagnostic aids with low variability are useful in the detection and standardization of results and in the targets' assessment. Moreover, if mucosal healing could be perceived as a realistic target, a concept that moves forward and takes to the extreme the previous idea is disease clearance. Even though a clear definition is still lacking, this objective includes simultaneous clinical, 
endoscopic, and histological remission of disease. It follows that the modern algorithms presented in the current review could help in the detection of this ambitious goal.

All the reported experiences improved the awareness about AI potential strengths and limitations. Most were nonrandomized and retrospective with small sample sizes. In addition, very limited studies were conducted to test AI support in the detection of dysplasia and neoplasia in patients with IBD. We believe these limitations should be overcome before AI becomes part of real-life practice.

In the context of $\mathrm{AI}$ and big data, a future perspective is the creation of algorithms for diagnosis and monitoring of IBD based not only on endoscopic, but also on clinical and histological data in order to have a complete overview of all disease features.

Author Contributions: Writing-original draft preparation, V.S., A.Z. and G.F. (Gianluca Franchellucci); writing-review and editing, V.S., A.Z., G.F. (Gianluca Franchellucci), M.A., G.F. (Gionata Fiorino), F.F., F.D., S.D. and S.A.A.; supervision, A.Z., S.D. and S.A.A. All authors have read and agreed to the published version of the manuscript.

Funding: This research received no external funding.

Informed Consent Statement: Not applicable.

Conflicts of Interest: M.A. received consulting fees from Nikkiso Europe, Mundipharma, Janssen, Abbvie, and Pfizer; F.F. received consulting fees from Amgen and Abbvie and lecture fees from Janssen and Pfizer; G.F. (Gionata Fiorino) served as a consultant and advisory board member for Takeda, Abbvie, Janssen, Pfizer, Celltrion, Sandoz, AlfaSigma, Samsung Bioepis, Amgen, Roche, Ferring, Mylan, and Gilead/Galapagos. S.D. has served as a speaker, consultant, and advisory board member for Schering-Plough, AbbVie, Actelion, Alphawasserman, AstraZeneca, Cellerix, Cosmo Pharmaceuticals, Ferring, Genentech, Grunenthal, Johnson and Johnson, Millenium Takeda, MSD, Nikkiso Europe GmbH, Novo Nordisk, Nycomed, Pfizer, Pharmacosmos, UCB Pharma, and Vifor. The remaining authors declare no competing interest.

\section{References}

1. Windsor, J.W.; Kaplan, G.G. Evolving Epidemiology of IBD. Curr. Gastroenterol. Rep. 2019, 21, 40. [CrossRef]

2. Wright, E.K.; Kamm, M.A. Impact of Drug Therapy and Surgery on Quality of Life in Crohn's Disease. Inflamm. Bowel Dis. 2015, 21, 1187-1194. [CrossRef] [PubMed]

3. Feuerstein, J.D.; Cheifetz, A.S. Crohn Disease: Epidemiology, Diagnosis, and Management. Mayo Clin. Proc. 2017, 92, 1088-1103. [CrossRef] [PubMed]

4. Maaser, C.; Sturm, A.; Vavricka, S.R.; Kucharzik, T.; Fiorino, G.; Annese, V.; Calabrese, E.; Baumgart, D.C.; Bettenworth, D.; Borralho Nunes, P.; et al. ECCO-ESGAR Guideline for Diagnostic Assessment in IBD Part 1: Initial diagnosis, monitoring of known IBD, detection of complications. J. Crohn's Colitis 2019, 13, 144K-164K. [CrossRef]

5. Solitano, V.; D’Amico, F.; Allocca, M.; Fiorino, G.; Zilli, A.; Loy, L.; Gilardi, D.; Radice, S.; Correale, C.; Danese, S.; et al. Re-discovering Histology: What Is New in Endoscopy for Inflammatory Bowel Disease? Ther. Adv. Gastroenterol. 2021, 14, 1-19.

6. Lui, T.K.L.; Leung, W.K. Is artificial intelligence the final answer to missed polyps in colonoscopy? World J. Gastroenterol. 2020, 26, 5248-5255. [CrossRef]

7. Swager, A.-F.; van der Sommen, F.; Klomp, S.; Zinger, S.; Meijer, S.; Schoon, E.J.; Bergman, J.J.; de With, P.H.; Curvers, W.L. Computer-aided detection of early Barrett's neoplasia using volumetric laser endomicroscopy. Gastrointest. Endosc. 2017, 86, 839-846. [CrossRef] [PubMed]

8. Repici, A.; Badalamenti, M.; Maselli, R.; Correale, L.; Radaelli, F.; Rondonotti, E.; Ferrara, E.; Spadaccini, M.; Alkandari, A.; Fugazza, A.; et al. Efficacy of Real-Time Computer-Aided Detection of Colorectal Neoplasia in a Randomized Trial. Gastroenterol. 2020, 159, 512-520.e7. [CrossRef]

9. Klare, P.; Sander, C.; Prinzen, M.; Haller, B.; Nowack, S.; Abdelhafez, M.; Poszler, A.; Brown, H.; Wilhelm, D.; Schmid, R.M.; et al. Automated polyp detection in the colorectum: A prospective study (with videos). Gastrointest. Endosc. 2019, 89, 576-582.e1. [CrossRef]

10. Khorasani, H.M.; Usefi, H.; Peña-Castillo, L. Detecting ulcerative colitis from colon samples using efficient feature selection and machine learning. Sci. Rep. 2020, 10, 13744. [CrossRef]

11. Waljee, A.K.; Wallace, B.; Cohen-Mekelburg, S.; Liu, Y.; Liu, B.; Sauder, K.; Stidham, R.W.; Zhu, J.; Higgins, P.D.R. Development and Validation of Machine Learning Models in Prediction of Remission in Patients with Moderate to Severe Crohn Disease. JAMA Netw. Open 2019, 2, e193721. [CrossRef] 
12. Travis, S.P.L.; Schnell, D.; Krzeski, P.; Abreu, M.T.; Altman, D.G.; Colombel, J.-F.; Feagan, B.G.; Hanauer, S.B.; Lémann, M.; Lichtenstein, G.R.; et al. Developing an instrument to assess the endoscopic severity of ulcerative colitis: The Ulcerative Colitis Endoscopic Index of Severity (UCEIS). Gut 2011, 61, 535-542. [CrossRef] [PubMed]

13. Gralnek, I.M.; Defranchis, R.; Seidman, E.; Leighton, J.A.; Legnani, P.; Lewis, B.S. Development of a capsule endoscopy scoring index for small bowel mucosal inflammatory change. Aliment. Pharmacol. Ther. 2007, 27, 146-154. [CrossRef]

14. Niv, Y.; Ilani, S.; Levi, Z.; Hershkowitz, M.; Niv, E.; Fireman, Z.; Odonnel, S.; Omorain, C.; Eliakim, R.; Scapa, E.; et al. Vali-dation of the Capsule Endoscopy Crohns Disease Activity Index (CECDAI or Niv Score): A Multicenter Prospective Study. Endoscopy 2012, 44, 21-26. [PubMed]

15. Rosa, B.; Pinho, R.; De Ferro, S.M.; Almeida, N.; Cotter, J.; Saraiva, M.M. Endoscopic Scores for Evaluation of Crohn's Disease Activity at Small Bowel Capsule Endoscopy: General Principles and Current Applications. GE Port. J. Gastroenterol. 2016, 23, 36-41. [CrossRef]

16. Yu, K.H.; Beam, A.L.; Kohane, I.S. Artificial Intelligence in Healthcare. Nat. Biomed. Eng. 2018, 2, 719-731. [CrossRef] [PubMed]

17. El Hajjar, A.; Rey, J.-F. Artificial intelligence in gastrointestinal endoscopy: General overview. Chin. Med. J. 2020, 133, 326-334. [CrossRef]

18. Nakase, H.; Hirano, T.; Wagatsuma, K.; Ichimiya, T.; Yamakawa, T.; Yokoyama, Y.; Hayashi, Y.; Hirayama, D.; Kazama, T.; Yoshii, S.; et al. Artificial intelligence-assisted endoscopy changes the definition of mucosal healing in ulcerative colitis. Dig. Endosc. 2020, 33, 903-911. [CrossRef] [PubMed]

19. Tziortziotis, I.; Laskaratos, F.-M.; Coda, S. Role of Artificial Intelligence in Video Capsule Endoscopy. Diagnostics 2021, 11, 1192. [CrossRef]

20. Noble, W.S. What Is a Support Vector Machine? Nat. Biotechnol. 2006, 24, 1565-1567. [CrossRef] [PubMed]

21. Chan, H.-P.; Samala, R.K.; Hadjiiski, L.M.; Zhou, C. Deep Learning in Medical Image Analysis. Adv. Exp. Med. Biol. 2020, 1213, 3-21. [CrossRef]

22. Lecun, Y.; Bengio, Y.; Hinton, G. Deep Learning. Nature 2015, 521, 436-444. [CrossRef]

23. Choi, J.; Shin, K.; Jung, J.; Bae, H.-J.; Kim, D.H.; Byeon, J.-S.; Kim, N. Convolutional Neural Network Technology in Endoscopic Imaging: Artificial Intelligence for Endoscopy. Clin. Endosc. 2020, 53, 117-126. [CrossRef]

24. Eickhoff, A.; Van Dam, J.; Jakobs, R.; Kudis, V.; Hartmann, D.; Damian, U.; Weickert, U.; Schilling, D.; Riemann, J.F. ComputerAssisted Colonoscopy (The NeoGuide Endoscopy System): Results of the First Human Clinical Trial ("PACE Study"). Am. J. Gastroenterol. 2007, 102, 261-266. [CrossRef]

25. Sumiyama, K.; Futakuchi, T.; Kamba, S.; Matsui, H.; Tamai, N. Artificial intelligence in endoscopy: Present and future perspectives. Dig. Endosc. 2021, 33, 218-230. [CrossRef]

26. Ichimasa, K.; Kudo, S.-E.; Mori, Y.; Misawa, M.; Matsudaira, S.; Kouyama, Y.; Baba, T.; Hidaka, E.; Wakamura, K.; Hayashi, T.; et al. Artificial intelligence may help in predicting the need for additional surgery after endoscopic resection of T1 colorectal cancer. Endoscopy 2018, 50, 230-240. [CrossRef]

27. Hassan, C.; Wallace, M.B.; Sharma, P.; Maselli, R.; Craviotto, V.; Spadaccini, M.; Repici, A. New artificial intelligence system: First validation study versus experienced endoscopists for colorectal polyp detection. Gut 2019, 69, 799-800. [CrossRef]

28. Hassan, C.; Badalamenti, M.; Maselli, R.; Correale, L.; Iannone, A.; Radaelli, F.; Rondonotti, E.; Ferrara, E.; Spadaccini, M.; Alkandari, A.; et al. Computer-aided detection-assisted colonoscopy: Classification and relevance of false positives. Gastrointest. Endosc. 2020, 92, 900-904.e4. [CrossRef] [PubMed]

29. Hassan, C.; Spadaccini, M.; Iannone, A.; Maselli, R.; Jovani, M.; Chandrasekar, V.T.; Antonelli, G.; Yu, H.; Areia, M.; Dinis-Ribeiro, M.; et al. Performance of artificial intelligence in colonoscopy for adenoma and polyp detection: A systematic review and meta-analysis. Gastrointest. Endosc. 2021, 93, 77-85.e6. [CrossRef] [PubMed]

30. Mossotto, E.; Ashton, J.J.; Coelho, T.; Beattie, R.M.; MacArthur, B.D.; Ennis, S. Classification of Paediatric Inflammatory Bowel Disease using Machine Learning. Sci. Rep. 2017, 7, 2427. [CrossRef] [PubMed]

31. Quénéhervé, L.; David, G.; Bourreille, A.; Hardouin, J.B.; Rahmi, G.; Neunlist, M.; Brégeon, J.; Coron, E. Quantitative assessment of mucosal architecture using computer-based analysis of confocal laser endomicroscopy in inflammatory bowel diseases. Gastrointest. Endosc. 2019, 89, 626-636. [CrossRef]

32. Kiesslich, R.; Burg, J.; Vieth, M.; Gnaendiger, J.; Enders, M.; Delaney, P.; Polglase, A.; McLaren, W.; Janell, D.; Thomas, S.; et al. Confocal laser endoscopy for diagnosing intraepithelial neoplasias and colorectal cancer in vivo. Gastroenterology 2004, 127, 706-713. [CrossRef] [PubMed]

33. De Chambrun, G.P.; Blanc, P.; Peyrin-Biroulet, L. Current evidence supporting mucosal healing and deep remission as important treatment goals for inflammatory bowel disease. Expert Rev. Gastroenterol. Hepatol. 2016, 10, 1-13. [CrossRef] [PubMed]

34. De Chambrun, G.P.; Peyrin-Biroulet, L.; Lémann, M.; Colombel, J.-F. Clinical implications of mucosal healing for the management of IBD. Nat. Rev. Gastroenterol. Hepatol. 2009, 7, 15-29. [CrossRef] [PubMed]

35. Ozawa, T.; Ishihara, S.; Fujishiro, M.; Saito, H.; Kumagai, Y.; Shichijo, S.; Aoyama, K.; Tada, T. Novel computer-assisted diagnosis system for endoscopic disease activity in patients with ulcerative colitis. Gastrointest. Endosc. 2019, 89, 416-421.e1. [CrossRef] [PubMed]

36. Stidham, R.W.; Liu, W.; Bishu, S.; Rice, M.D.; Higgins, P.D.R.; Zhu, J.; Nallamothu, B.K.; Waljee, A.K. Performance of a Deep Learning Model vs Human Reviewers in Grading Endoscopic Disease Severity of Patients with Ulcerative Colitis. JAMA Netw. Open 2019, 2, e193963. [CrossRef] 
37. Gottlieb, K.; Requa, J.; Karnes, W.; Gudivada, R.C.; Shen, J.; Rael, E.; Arora, V.; Dao, T.; Ninh, A.; McGill, J. Central Reading of Ulcerative Colitis Clinical Trial Videos Using Neural Networks. Gastroenterology 2021, 160, 710-719.e2. [CrossRef]

38. Yao, H.; Najarian, K.; Gryak, J.; Bishu, S.; Rice, M.D.; Waljee, A.K.; Wilkins, H.J.; Stidham, R.W. Fully automated endoscopic disease activity assessment in ulcerative colitis. Gastrointest. Endosc. 2021, 93, 728-736.e1. [CrossRef] [PubMed]

39. Bhambhvani, H.P.; Zamora, A. Deep learning enabled classification of Mayo endoscopic subscore in patients with ulcerative colitis. Eur. J. Gastroenterol. Hepatol. 2021, 33, 645-649. [CrossRef]

40. Becker, B.G.; Arcadu, F.; Thalhammer, A.; Serna, C.G.; Feehan, O.; Drawnel, F.; Oh, Y.S.; Prunotto, M. Training and deploying a deep learning model for endoscopic severity grading in ulcerative colitis using multicenter clinical trial data. Ther. Adv. Gastrointest. Endosc. 2021, 14, 1-15. [CrossRef]

41. Maeda, Y.; Kudo, S.-E.; Ogata, N.; Misawa, M.; Iacucci, M.; Homma, M.; Nemoto, T.; Takishima, K.; Mochida, K.; Miyachi, H.; et al. Evaluation in real-time use of artificial intelligence during colonoscopy to predict relapse of ulcerative colitis: A prospective study. Gastrointest Endosc. 2021, 22, S0016-5107(21)01731-4, Epub ahead of print. [CrossRef]

42. Takenaka, K.; Ohtsuka, K.; Fujii, T.; Negi, M.; Suzuki, K.; Shimizu, H.; Oshima, S.; Akiyama, S.; Motobayashi, M.; Nagahori, M.; et al. Development and Validation of a Deep Neural Network for Accurate Evaluation of Endoscopic Images from Patients with Ulcerative Colitis. Gastroenterology 2020, 158, 2150-2157. [CrossRef]

43. Park, S.; Abdi, T.; Gentry, M.; Laine, L. Histological Disease Activity as a Predictor of Clinical Relapse Among Patients With Ulcerative Colitis: Systematic Review and Meta-Analysis. Am. J. Gastroenterol. 2016, 111, 1692-1701. [CrossRef] [PubMed]

44. Maeda, Y.; Kudo, S.-E.; Mori, Y.; Misawa, M.; Ogata, N.; Sasanuma, S.; Wakamura, K.; Oda, M.; Mori, K.; Ohtsuka, K. Fully automated diagnostic system with artificial intelligence using endocytoscopy to identify the presence of histologic inflammation associated with ulcerative colitis (with video). Gastrointest. Endosc. 2019, 89, 408-415. [CrossRef] [PubMed]

45. Takamaru, H.; Wu, S.Y.S.; Saito, Y. Endocytoscopy: Technology and clinical application in the lower GI tract. Transl. Gastroenterol. Hepatol. 2020, 5, 40. [CrossRef] [PubMed]

46. Honzawa, Y.; Matsuura, M.; Higuchi, H.; Sakurai, T.; Seno, H.; Nakase, H. A novel endoscopic imaging system for quantitative evaluation of colonic mucosal inflammation in patients with quiescent ulcerative colitis. Endosc. Int. Open 2020, 8, E41-E49. [CrossRef]

47. Bossuyt, P.; Nakase, H.; Vermeire, S.; De Hertogh, G.; Eelbode, T.; Ferrante, M.; Hasegawa, T.; Willekens, H.; Ikemoto, Y.; Makino, T.; et al. Automatic, computer-aided determination of endoscopic and histological inflammation in patients with mild to moderate ulcerative colitis based on red density. Gut 2020, 69, 1778-1786. [CrossRef] [PubMed]

48. McCain, J.D.; Pasha, S.F.; Leighton, J.A. Role of Capsule Endoscopy in Inflammatory Bowel Disease. Gastrointest. Endosc. Clin. N. Am. 2021, 31, 345-361. [CrossRef]

49. Girgis, H.Z.; Mitchell, B.R.; Dassopoulos, T.; Mullin, G.; Hager, G. An intelligent system to detect Crohn's disease inflammation in Wireless Capsule Endoscopy videos. In Proceedings of the 2010 IEEE International Symposium on Biomedical Imaging: From Nano to Macro (IEEE 2010), Rotterdam, The Netherlands, 14-17 April 2010; pp. 1373-1376.

50. Kumar, R.; Zhao, Q.; Seshamani, S.; Mullin, G.; Hager, G.; Dassopoulos, T. Assessment of Crohn's Disease Lesions in Wireless Capsule Endoscopy Images. IEEE Trans. Biomed. Eng. 2011, 59, 355-362. [CrossRef] [PubMed]

51. Charisis, V.S.; Hadjileontiadis, L.J. Potential of hybrid adaptive filtering in inflammatory lesion detection from capsule endoscopy images. World J. Gastroenterol. 2016, 22, 8641-8657. [CrossRef] [PubMed]

52. Klang, E.; Barash, Y.; Margalit, R.Y.; Soffer, S.; Shimon, O.; Albshesh, A.; Ben-Horin, S.; Amitai, M.M.; Eliakim, R.; Kopylov, U. Deep learning algorithms for automated detection of Crohn's disease ulcers by video capsule endoscopy. Gastrointest. Endosc. 2020, 91, 606-613.e2. [CrossRef] [PubMed]

53. Klang, E.; Grinman, A.; Soffer, S.; Yehuda, R.M.; Barzilay, O.; Amitai, M.M.; Konen, E.; Ben-Horin, S.; Eliakim, R.; Barash, Y.; et al. Automated Detection of Crohn's Disease Intestinal Strictures on Capsule Endoscopy Images Using Deep Neural Networks. J. Crohn's Coliti 2021, 15, 749-756. [CrossRef] [PubMed]

54. Aoki, T.; Yamada, A.; Aoyama, K.; Saito, H.; Tsuboi, A.; Nakada, A.; Niikura, R.; Fujishiro, M.; Oka, S.; Ishihara, S.; et al Automatic detection of erosions and ulcerations in wireless capsule endoscopy images based on a deep convolutional neural network. Gastrointest. Endosc. 2019, 89, 357-363.e2. [CrossRef] [PubMed]

55. Barash, Y.; Azaria, L.; Soffer, S.; Yehuda, R.M.; Shlomi, O.; Ben-Horin, S.; Eliakim, R.; Klang, E.; Kopylov, U. Ulcer severity grading in video capsule images of patients with Crohn's disease: An ordinal neural network solution. Gastrointest. Endosc. 2021, 93, 187-192. [CrossRef] [PubMed]

56. Majtner, T.; Brodersen, J.B.; Herp, J.; Kjeldsen, J.; Halling, M.L.; Jensen, M.D. A deep learning framework for autonomous detection and classification of Crohn's disease lesions in the small bowel and colon with capsule endoscopy. Endosc. Int. Open 2021, 9, E1361-E1370. [CrossRef] [PubMed]

57. Ferreira, J.P.S.; de Mascarenhas Saraiva, M.J.D.Q.E.C.; Afonso, J.P.L.; Ribeiro, T.F.C.; Cardoso, H.M.C.; Andrade, A.P.R.; Parente, M.P.L.; Jorge, R.N.; Lopes, S.I.O.; de Macedo, G.M.G. Identification of Ulcers and Erosions by the Novel Pillcam ${ }^{\text {TM }}$ Crohn's Capsule Using a Convolutional Neural Network: A Multicentre Pilot Study. J. Crohn's Colitis 2021, 1-4. [CrossRef]

58. Sidhu, R.; Sanders, D.S.; Morris, A.J.; McAlindon, M.E. Guidelines on small bowel enteroscopy and capsule endoscopy in adults. Gut 2007, 57, 125-136. [CrossRef] 
59. Flamant, M.; Trang, C.; Maillard, O.; Sacher-Huvelin, S.; Le Rhun, M.; Galmiche, J.-P.; Bourreille, A. The Prevalence and Outcome of Jejunal Lesions Visualized by Small Bowel Capsule Endoscopy in Crohn's Disease. Inflamm. Bowel Dis. 2013, 19, 1390-1396. [CrossRef] [PubMed]

60. Carvalho, P.B.; Rosa, B.; Cotter, J. Mucosal healing in Crohn's disease-Are we reaching as far as possible with capsule endoscopy? J. Crohn's Colitis 2014, 8, 1566-1567. [CrossRef]

61. Eaden, J.A.; Abrams, K.R.; Mayberry, J.F. The risk of colorectal cancer in ulcerative colitis: A meta-analysis. Gut 2001, 48, 526-535. [CrossRef] [PubMed]

62. Magro, F.; Gionchetti, P.; Eliakim, R.; Ardizzone, S.; Armuzzi, A.; Barreiro-de Acosta, M.; Burisch, J.; Gecse, K.B.; Hart, A.L.; Hindryckx, P.; et al. Third European evidence-based consensus on diagnosis and management of ulcerative colitis. Part 1: Definitions, Diagnosis, Extra-intestinal Manifestations, Pregnancy, Cancer Surveillance, Surgery, and Ileo-anal Pouch Disorders. J. Crohn's Colitis 2017, 11, 649-670. [CrossRef] [PubMed]

63. Maeda, Y.; Kudo, S.E.; Ogata, N.; Misawa, M.; Mori, Y.; Mori, K.; Ohtsuka, K. Can Artificial Intelligence Help to Detect Dys-plasia in Patients with Ulcerative Colitis? Endoscopy 2021, 53, E273-E274. [PubMed]

64. Kudo, S.-E.; Misawa, M.; Mori, Y.; Hotta, K.; Ohtsuka, K.; Ikematsu, H.; Saito, Y.; Takeda, K.; Nakamura, H.; Ichimasa, K.; et al. Artificial Intelligence-assisted System Improves Endoscopic Identification of Colorectal Neoplasms. Clin. Gastroenterol. Hepatol. 2020, 18, 1874-1881.e2. [CrossRef] [PubMed]

65. Fukunaga, S.; Kusaba, Y.; Ohuchi, A.; Nagata, T.; Mitsuyama, K.; Tsuruta, O.; Torimura, T. Is artificial intelligence a superior diagnostician in ulcerative colitis? Laryngo-Rhino-Otologie 2021, 53, E75-E76. [CrossRef] [PubMed] 